\title{
Synthesis of the superfine high-entropy zirconate nanopowders by polymerized complex method
}

\author{
Yangjie HAN, Renwang YU, Honghua LIU, Yanhui CHU* \\ School of Materials Science and Engineering, South China University \\ of Technology, Guangzhou 510641, China
}

Received: March 15, 2021; Revised: July 28, 2021; Accepted: July 31, 2021

(C) The Author(s) 2021.

\begin{abstract}
The high-purity and superfine high-entropy zirconate nanopowders, namely $\left(\mathrm{Y}_{0.25} \mathrm{La}_{0.25} \mathrm{Sm}_{0.25} \mathrm{Eu}_{0.25}\right)_{2} \mathrm{Zr}_{2} \mathrm{O}_{7}$ nanopowders, without agglomeration, were successfully synthesized via polymerized complex method at low temperatures for the first time. The results showed that the crystallinity degree, lattice strain, and particle size of the as-synthesized powders were gradually enhanced with the increase of the synthesis temperature from 800 to $1300{ }^{\circ} \mathrm{C}$. The as-synthesized powders involved fluorite phase in the range of $800-1200{ }^{\circ} \mathrm{C}$ while they underwent the phase evolution from fluorite to pyrochlore at $1300{ }^{\circ} \mathrm{C}$. It is worth mentioning that the as-synthesized powders at $900{ }^{\circ} \mathrm{C}$ are of the highest quality among all the as-synthesized powders, which is due to the fact that they not only possess the particle size of $11 \mathrm{~nm}$ without agglomeration, but also show high purity and good compositional uniformity.
\end{abstract}

Keywords: high-entropy oxides; zirconates; nanopowders; polymerized complex method

\section{Introduction}

Since their discovery in 2015 , high-entropy oxides, namely multicomponent ionic compounds, have been of considerable interest for their immense composition space, unique microstructure, adjustable properties, and great potential applications [1-4]. Up to now, great efforts have been devoted to explore a variety of high-entropy oxides with different crystalline structures, such as rock salt [1,5], perovskite [6,7], and fluorite $[8,9]$. The high-entropy zirconates, a representative member of high-entropy fluorite oxides, have been attracting considerable research interest in recent years for their potential applications in the thermal barrier

\footnotetext{
* Corresponding author.

E-mail: chuyh@scut.edu.cn
}

coatings, solid electrolytes, and luminescence medium due to their attractive physical-chemical properties, such as good corrosion resistance, high ion conductivity, high refractive index and optical transparency, and ultra-low thermal conductivity [10-13]. As a result, they are expected to be widely used. It is well known that the synthesis of high-entropy zirconate powders is critical for implementing the extensive applications of highentropy zirconates. Till today, only combustion synthesis technique has been developed to synthesize high-entropy zirconate nanopowders [14]. However, it required the high synthesis temperatures, and simultaneously the as-synthesized nanopowders were severely agglomerated, which severely impeded the extensive applications of high-entropy zirconates. Therefore, it is essential to develop the low-temperature synthesis technique to synthesize highentropy zirconate nanopowders without agglomeration.

The polymerized complex method, as a representative 
synthesis technique of oxide powders, possesses a series of good characteristics, including simple process, low synthesis temperature, high purity, and superfine product without agglomeration, etc., which has been widely used for the low-temperature synthesis of the various individual rare-earth zirconate nanopowders without agglomeration in the past several decades $[15,16]$. Nevertheless, to the best of our knowledge, there is little report so far on the synthesis of highentropy zirconate nanopowders via polymerized complex method. Provided that the polymerized complex method is proposed to synthesize high-entropy zirconate nanopowders, it can be expected to achieve the lowtemperature synthesis of high-purity and superfine highentropy zirconate nanopowders without agglomeration, which finally improves the extensive applications of high-entropy zirconates.

In this work, the polymerized complex method was proposed to synthesize the high-purity and superfine high-entropy zirconate nanopowders, namely $\left(\mathrm{Y}_{0.25} \mathrm{La}_{0.25} \mathrm{Sm}_{0.25} \mathrm{Eu}_{0.25}\right)_{2} \mathrm{Zr}_{2} \mathrm{O}_{7}\left(\mathrm{RE}_{2} \mathrm{Zr}_{2} \mathrm{O}_{7}-1\right)$ nanopowders, without agglomeration at low temperatures, for the first time. The effect of synthesis temperature on the phase composition, crystallinity degree, lattice strain, and particle size of the as-synthesized powders was first studied, and then the morphology, microstructure, and compositional uniformity of the as-synthesized powders were investigated in detail.

\section{Experimental}

In our experiment, the commercially available lanthanide nitrate hexahydrates $\left(\mathrm{Ln}\left(\mathrm{NO}_{3}\right)_{3} \cdot 6 \mathrm{H}_{2} \mathrm{O}(\mathrm{Ln}=\right.$ Y, La, Sm, and Eu), 99.5\% purity; Shanghai McLean
Biochemical Technology Co., Ltd., China) and zirconium nitrate $\left(\mathrm{Zr}\left(\mathrm{NO}_{3}\right)_{4} \cdot 5 \mathrm{H}_{2} \mathrm{O}\right.$, $99.99 \%$ purity; Shanghai McLean Biochemical Technology Co., Ltd., China) were utilized as the raw materials to fabricate the preceramic polymer for $\mathrm{RE}_{2} \mathrm{Zr}_{2} \mathrm{O}_{7}-1$ products. Citric acid $\left(\mathrm{C}_{6} \mathrm{H}_{8} \mathrm{O}_{7} \cdot \mathrm{H}_{2} \mathrm{O}\right.$, CA, analytical reagent; Shanghai Runjie Chemical Reagent Co., Ltd., China) was used as the complexing agent, and ethylene glycol $\left(\mathrm{C}_{2} \mathrm{H}_{6} \mathrm{O}_{2}\right.$, EG, analytical reagent; Shanghai Runjie Chemical Reagent Co., Ltd., China) was used as the dispersant. The details of the synthesis process of $\mathrm{RE}_{2} \mathrm{Zr}_{2} \mathrm{O}_{7}-1$ are outlined in Fig. 1. $\mathrm{Ln}\left(\mathrm{NO}_{3}\right)_{3} \cdot 6 \mathrm{H}_{2} \mathrm{O}$ and $\mathrm{Zr}\left(\mathrm{NO}_{3}\right)_{4} \cdot 5 \mathrm{H}_{2} \mathrm{O}$ were first dissolved in distilled water with the $\mathrm{Zr}^{4+} / \mathrm{Ln}^{3+}$ molar ratio of $1: 1$, and then the $\mathrm{pH}$ of the mixed solution was adjusted to a value of 6 by adding a dilute ammonia solution. Furthermore, CA was added to EG with the molar ratio of $2: 3$ and stirred at $100{ }^{\circ} \mathrm{C}$ to form a transparent solution [16]. Subsequently, the as-obtained two mixed solutions were directly mixed with the $\mathrm{CA} / \mathrm{Zr}^{4+}$ molar ratio of 2:1 [16]. The resultant solution was heated to $130{ }^{\circ} \mathrm{C}$ with magnetic stirring to form the polymeric precursor by the polymerization and complexation reactions. Finally, the precursor was dried at $130{ }^{\circ} \mathrm{C}$, and calcinated in a temperature range from 800 to $1300{ }^{\circ} \mathrm{C}$ for $2 \mathrm{~h}$ in a muffle furnace in air with a heating rate of $7{ }^{\circ} \mathrm{C} / \mathrm{min}$, followed by natural cooling to the room temperature in air.

The thermogravimetry, differential scanning calorimetry, and differential thermogravimetry (TG-DSC-DTG) analysis of the precursors was carried out using a Netzsch Instrument STA 449 F5 Jupiter system. Measurements were taken under air atmosphere from room temperature to $1000{ }^{\circ} \mathrm{C}$ at a heating rate of $10{ }^{\circ} \mathrm{C} / \mathrm{min}$. Phase compositions of the as-synthesized products were investigated via X-ray diffraction (XRD; X'pert PRO,

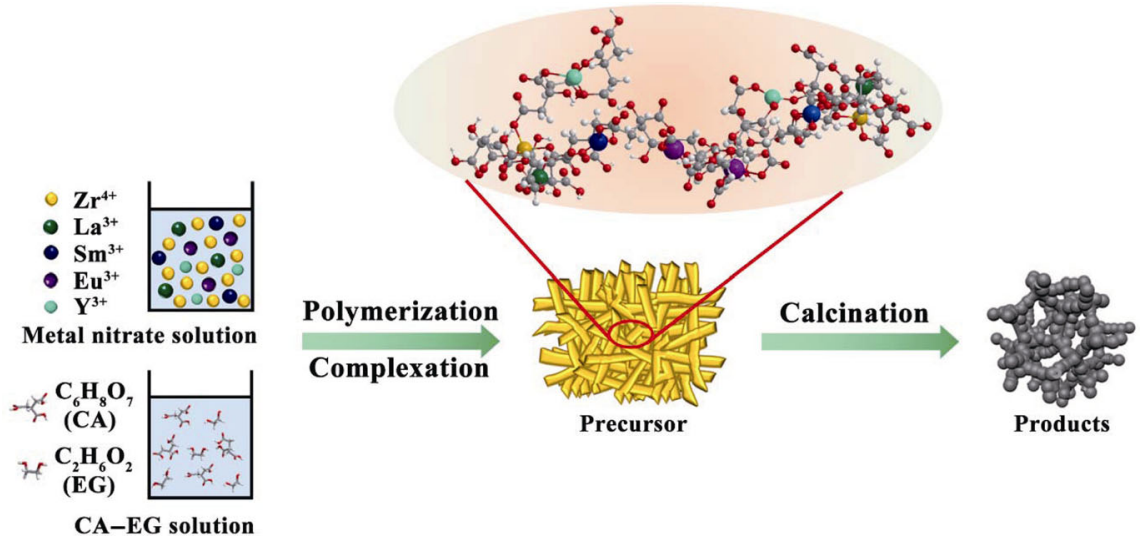

Fig. 1 Schematic diagram of the synthesis process of $\mathrm{RE}_{2} \mathrm{Zr}_{2} \mathrm{O}_{7}-1$ nanopowders. 
PANalytical, Almelo, the Netherlands) with a scanning mode in $2 \theta$ ranging from $10^{\circ}$ to $80^{\circ}$ and a scanning step size of $0.04^{\circ}$ at a scanning rate of $2\left(^{\circ}\right) / \mathrm{min}$. Rietveld analyses were performed with the software GSAS [17]. The crystallite sizes $(D)$ of the as-synthesized samples were calculated by the Scherrer equation:

$$
D=\frac{k \lambda}{\beta_{\mathrm{D}} \cos \theta}
$$

where $\lambda$ is the wave length of $\mathrm{Cu}-\mathrm{K} \alpha$ radiation $(0.15406 \mathrm{~nm}), k$ is the constant parameter equal to 0.94 , $\theta$ is the Bragg angle, and $\beta_{\mathrm{D}}$ is the peak full-width at half-maximum intensity in radian after correction for instrumental broadening. The lattice strain $(\varepsilon)$ was calculated by the size-strain plot (SSP) method [18]. Through the SSP method, the $\left(d_{h k l} \beta_{h k l} \cos \theta\right)^{2}$ was plotted versus $\left(d_{h k l}^{2} \beta_{h k l} \cos \theta\right)$ according to the following equation:

$$
\left(d_{h k l} \beta_{h k l} \cos \theta\right)^{2}=\frac{K}{D}\left(d_{h k l}^{2} \beta_{h k l} \cos \theta\right)+\left(\frac{\varepsilon}{2}\right)^{2}
$$

where $K$ is a constant that depends on the shape of particles, $d_{h k l}$ is the distance between adjacent planes that calculated from the Bragg equation, and $\beta_{h k l}$ is the peak full-width at half-maximum. The total percent crystallinity of the as-synthesized products was calculated by the following equation:

Crystallinty $=$

$$
\frac{\text { Area of crystalline peaks }}{\text { Area of all peaks (crystalline }+ \text { amorphous) }} \times 100 \%
$$

Microstructure and compositional uniformity of the as-synthesized products were characterized by scanning electron microscopy (SEM; Supra-55, Zeiss, Oberkochen, Germany) and transmission electron microscopy (TEM; Tecnai F30G2, FEI, Eindhoven, the Netherlands) equipped with the energy dispersive spectroscopy (EDS). In addition, the particle sizes were also measured for 50 individual nanoparticles for each sample using TEM analysis, in which a Gaussian fitting to these data yields an average particle size.

\section{Results and discussion}

The thermal decomposition of $\mathrm{RE}_{2} \mathrm{Zr}_{2} \mathrm{O}_{7}-1$ precursor was first investigated from room temperature to $1000{ }^{\circ} \mathrm{C}$ using TG-DSC-DTG analysis, as displayed in Fig. 2. The thermal decomposition process of the precursor

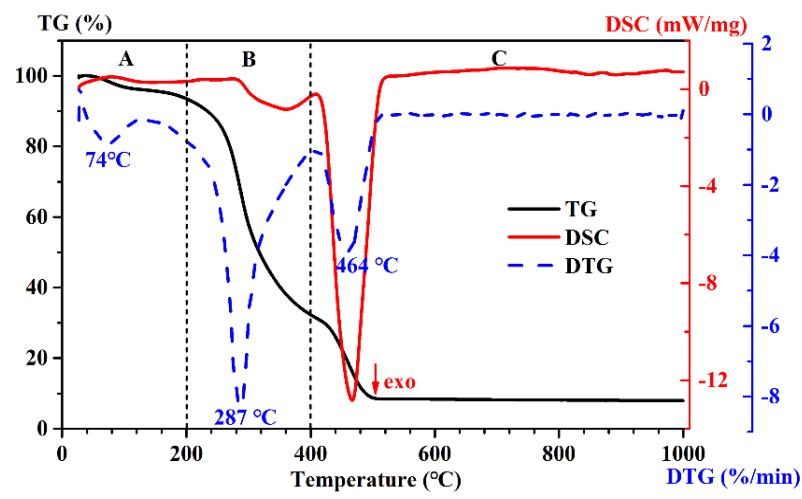

Fig. 2 TG-DSC-DTG curves of the precursor from room temperature to $1000{ }^{\circ} \mathrm{C}$ in air.

can be divided into three stages, marked as A, B, and C. During the stage A (below $200{ }^{\circ} \mathrm{C}$ ), the precursor underwent a small amount of weight loss $(\sim 6 \%)$ with a very small endothermic peak below $200{ }^{\circ} \mathrm{C}$, which could be attributed to the evaporation of water and residual solvents. During the stage B $\left(200-400{ }^{\circ} \mathrm{C}\right)$, the precursor underwent a large amount of weight loss $(\sim 65 \%)$, but only two small endothermic peaks could be observed at 325 and $350{ }^{\circ} \mathrm{C}$. This indicated that all kinds of organic matter for the precursor began to degrade and combust to generate the amorphous intermediates during this stage. During the stage $\mathrm{C}$ (above $400{ }^{\circ} \mathrm{C}$ ), an obvious sharp exothermic peak could be found at $464{ }^{\circ} \mathrm{C}$, while the weight loss of the precursor was only $20 \%$, which corresponded to the primary crystallizing process of the precursor that had been completely accompanied by combustion of any ignitable organics. In addition, no other exothermic or endothermic peaks were observed. These suggested the completion of organics decomposition and full crystallization of the precursor above $465{ }^{\circ} \mathrm{C}$. Consequently, the possible polymer-to-ceramic conversion process of the precursor could be described as follows: The precursor firstly underwent the degradation and combustion reactions to generate the amorphous intermediates by Eq. (4), as well as low-molecularweight gases, such as $\mathrm{CO}$ and $\mathrm{CO}_{2}$. Subsequently, the conversion of the amorphous intermediates into $\mathrm{RE}_{2} \mathrm{Zr}_{2} \mathrm{O}_{7}-1$ ceramics took place via Eq. (5):

Precursor $(\mathrm{s}) \rightarrow$ Intermediate $(\mathrm{s})+\mathrm{CO}(\mathrm{g})+\mathrm{CO}_{2}(\mathrm{~g})$

$$
\text { Intermediate }(\mathrm{s}) \rightarrow \mathrm{RE}_{2} \mathrm{Zr}_{2} \mathrm{O}_{7}-1(\mathrm{~s})+\mathrm{CO}(\mathrm{g})+\mathrm{CO}_{2}(\mathrm{~g})
$$

On the basis of TG-DSC-DTG analysis, the precursor was calcinated in a temperature range from 800 to $1300{ }^{\circ} \mathrm{C}$ to obtain $\mathrm{RE}_{2} \mathrm{Zr}_{2} \mathrm{O}_{7}-1$ products. XRD patterns 
of the as-synthesized products at different temperatures are shown in Fig. 3(a). It can be found that the single phase $\mathrm{RE}_{2} \mathrm{Zr}_{2} \mathrm{O}_{7}-1$ products can be successfully synthesized above $800{ }^{\circ} \mathrm{C}$. However, the crystallinity degree of the as-synthesized products at $800{ }^{\circ} \mathrm{C}$ was very low $(83 \%)$. As the temperatures increased from 800 to $1300{ }^{\circ} \mathrm{C}$, the crystallinity degree of the as-synthesized products was gradually enhanced, as displayed in Fig. 3(b). The crystallinity degree of the as-synthesized products at $1300{ }^{\circ} \mathrm{C}$ was up to $96 \%$. It is interesting to note that the as-synthesized products below $1200{ }^{\circ} \mathrm{C}$ can be identified as a fluorite phase. While they are composed of pyrochlore phase at $1300{ }^{\circ} \mathrm{C}$. This suggests that the phase evolution of the as-synthesized products has occurred from fluorite to pyrochlore at $1300{ }^{\circ} \mathrm{C}$. In addition, from the inset in Fig. 3, the position of the (111) peak is gradually shifted to the lower angle $\left(2 \theta=29.37^{\circ}\right.$ to $\left.2 \theta=29.24^{\circ}\right)$ with the increasing of the temperature from 800 to $1200{ }^{\circ} \mathrm{C}$, which can be the result of the thermally-induced expansion of the lattice constant. The refined unit cell parameters of the as-synthesized products at different temperatures from the XRD analysis are listed in Table 1. It can be found that the lattice constant is gradually increased with the increasing of the temperature from
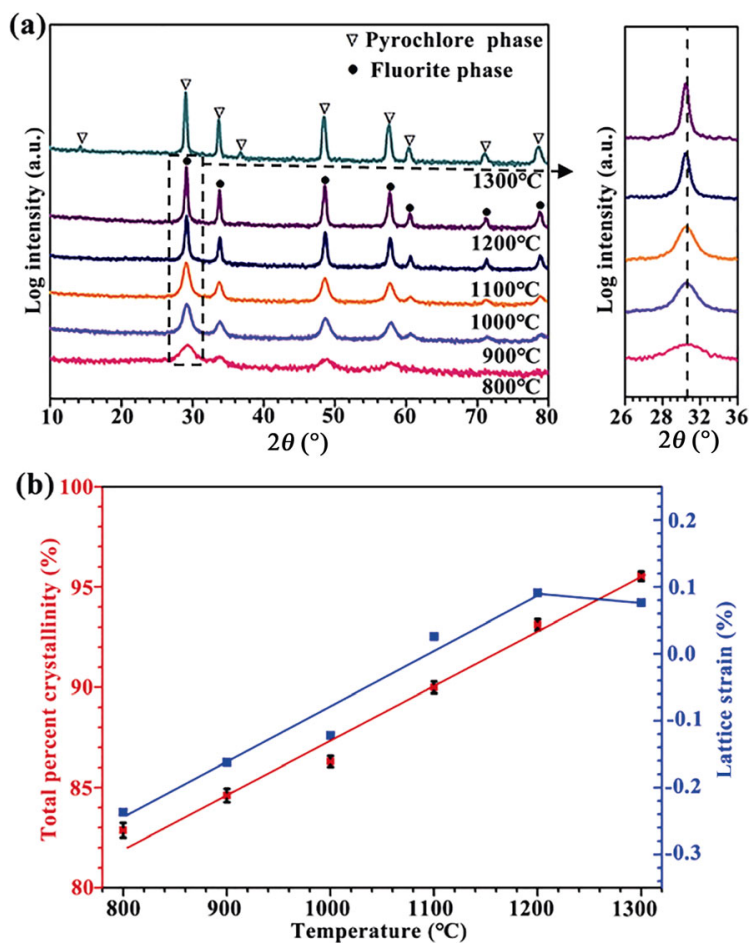

Fig. 3 (a) XRD patterns of the as-synthesized products at different temperatures and (b) total percent crystallinity and lattice strain of the as-synthesized products at different temperatures established through the SSP method.
800 to $1200{ }^{\circ} \mathrm{C}$, which is in good agreement with the variation trend of the (111) peak. In addition, the lattice strain of the as-synthesized products at different temperatures was calculated by the SSP method. Figure S1 in the Electronic Supplementary Material (ESM) illustrates the size-strain plots of the as-synthesized powders at different temperatures. According to Fig. S1 in the ESM, the $K$ and $\varepsilon$ values in Eq. (2) can be further calculated. As shown in Fig. 3(b), the lattice strain of the as-synthesized products increased from $-2.367 \times 10^{-3}$ to $9.147 \times 10^{-4}$ with the increasing of the temperature from 800 to $1200{ }^{\circ} \mathrm{C}$. When the temperature increased to $1300{ }^{\circ} \mathrm{C}$, although the phase evolution of the as-synthesized products has occurred from fluorite to pyrochlore, there is no great change in lattice strain, which is highly consistent with the variation trend of their lattice distortion amounts (Table 1).

Figure 4 shows the particle size calculated by Scherrer's equation and TEM analysis as a function of the temperature. Clearly, the variation trends of the as-obtained particle size as a function of the temperature were identical between Scherrer's equation and TEM analysis. That is to say, the particle size increased slowly below $1000{ }^{\circ} \mathrm{C}$ but increased significantly above $1000{ }^{\circ} \mathrm{C}$ with the temperature increasing from 800 to $1200{ }^{\circ} \mathrm{C}$. It should be noted that the particle size of the products at $900{ }^{\circ} \mathrm{C}$ is only about $11 \mathrm{~nm}$, which is consistent with that of the as-synthesized nanopowders by combustion synthesis technique at $1200{ }^{\circ} \mathrm{C}$ [14]. This result suggests that the polymerized complex method is superior to combustion synthesis technique in terms of synthesis temperature. The fluorite-pyrochlore transition temperatures of the as-synthesized $\mathrm{RE}_{2} \mathrm{Zr}_{2} \mathrm{O}_{7}-1$ products and the corresponding four individual zirconates are listed in Table 2. Obviously, the phase transition temperature of $\mathrm{RE}_{2} \mathrm{Zr}_{2} \mathrm{O}_{7}-1$ was higher than that of $\mathrm{La}_{2} \mathrm{Zr}_{2} \mathrm{O}_{7}$, but was

Table 1 Lattice constant (a) of the as-synthesized products at different temperatures by XRD refinement

\begin{tabular}{|c|c|c|c|c|c|c|}
\hline Product & $800{ }^{\circ} \mathrm{C}$ & $900{ }^{\circ} \mathrm{C}$ & $1000{ }^{\circ} \mathrm{C}$ & $1100{ }^{\circ} \mathrm{C}$ & $1200{ }^{\circ} \mathrm{C}$ & $1300{ }^{\circ} \mathrm{C}$ \\
\hline Space group & $F m \overline{3} m$ & $F m \overline{3} m$ & $F m \overline{3} m$ & $F m \overline{3} m$ & $F m \overline{3} m$ & $F d \overline{3} m$ \\
\hline Phase & Fluorite & Fluorite & Fluorite & Fluorite & Fluorite & Pyrochlore \\
\hline $\begin{array}{c}a(\AA) \text { from } \\
\text { XRD }\end{array}$ & 5.253 & 5.264 & 5.270 & 5.286 & 5.290 & 10.591 \\
\hline $\begin{array}{c}a(\AA) \text { from } \\
\text { Vegard's law }\end{array}$ & 5.280 & 5.280 & 5.280 & 5.280 & 5.280 & 10.571 \\
\hline $\begin{array}{c}a(\AA) \text { from } \\
\text { TEM }\end{array}$ & - & 5.260 & - & - & - & 10.590 \\
\hline
\end{tabular}




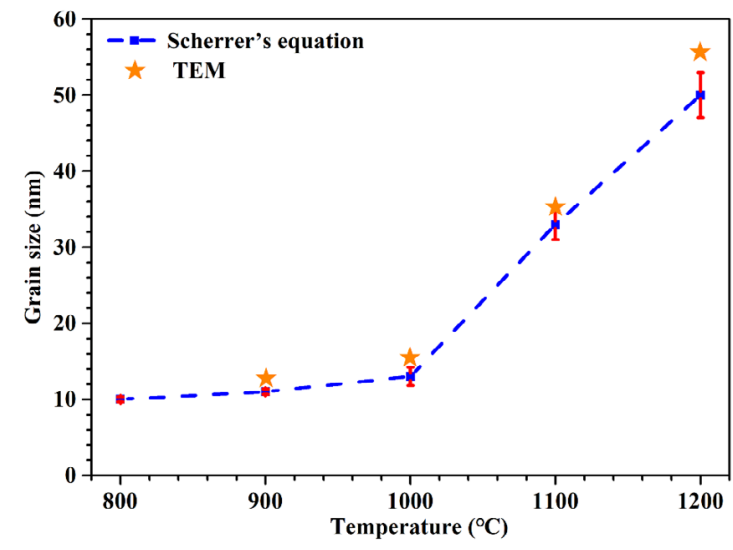

Fig. 4 Particle sizes of the as-synthesized products calculated by Scherrer's equation and TEM analysis as a function of the temperature.

Table 2 Lattice parameter (a) and fluorite-pyrochlore transition temperature of the as-synthesized $\mathrm{RE}_{2} \mathrm{Zr}_{2} \mathrm{O}_{7}-1$ and the corresponding four individual zirconates

\begin{tabular}{cccc}
\hline Material & $\begin{array}{c}a(\AA) \\
\text { (fluorite) }\end{array}$ & $\begin{array}{c}\text { Fluorite-pyrochlore } \\
\text { transition } \\
\text { temperature }\left({ }^{\circ} \mathrm{C}\right)\end{array}$ & Reference \\
\hline $\mathrm{Y}_{2} \mathrm{Zr}_{2} \mathrm{O}_{7}$ & - & - & - \\
$\mathrm{La}_{2} \mathrm{Zr}_{2} \mathrm{O}_{7}$ & 5.407 & 1000 & {$[20]$} \\
$\mathrm{Sm}_{2} \mathrm{Zr}_{2} \mathrm{O}_{7}$ & 5.270 & 1350 & {$[21]$} \\
$\mathrm{Eu}_{2} \mathrm{Zr}_{2} \mathrm{O}_{7}$ & 5.230 & 1400 & {$[22]$} \\
$\mathrm{RE}_{2} \mathrm{Zr}_{2} \mathrm{O}_{7}-1$ & 5.290 & 1300 & Present work \\
$\left(\right.$ at $\left.1200{ }^{\circ} \mathrm{C}\right)$ & & & \\
\hline
\end{tabular}

lower than that of $\mathrm{Sm}_{2} \mathrm{Zr}_{2} \mathrm{O}_{7}$ and $\mathrm{Eu}_{2} \mathrm{Zr}_{2} \mathrm{O}_{7}$, which may be due to the presence of the different lattice constants among them [19], as listed in Table 2.

Figure 5 displays the Rietveld refined XRD patterns of the as-synthesized products at 900 and $1300{ }^{\circ} \mathrm{C}$, from which it can be observed that there are the low related fitting parameter values for the as-synthesized products at 900 and $1300{ }^{\circ} \mathrm{C}$. This result indicates that the as-synthesized products at 900 and $1300{ }^{\circ} \mathrm{C}$ possess a fluorite phase with $F m \overline{3} m$ space group and a pyrochlore phase with $F d \overline{3} m$ space group, respectively. In addition, their refined unit cell parameters are listed in Table 1. It can be found that the refined lattice parameters by XRD not only are in good accordance with Vegard's law [23], but also are close to the measured results by TEM analysis, which further supports that the as-synthesized products are composed of $\mathrm{RE}_{2} \mathrm{Zr}_{2} \mathrm{O}_{7-1}$ phase.

Figure 6 shows the SEM images of the as-synthesized products at different temperatures. From Fig. 6(a), there are many submicron particles consisted of numerous superfine nanoparticle agglomerates in the as-synthesized products at $800{ }^{\circ} \mathrm{C}$, which might be due to the poor crystallization degree of the products at $800{ }^{\circ} \mathrm{C}$. When the temperature rose to $900{ }^{\circ} \mathrm{C}$, the as-synthesized products involved many superfine nanoparticles without agglomeration, as shown in Fig. 6(b), which were superior to the as-synthesized nanopowders by combustion synthesis technique at $1200{ }^{\circ} \mathrm{C}$ [14]. With the increase of the temperature from 900 to $1200{ }^{\circ} \mathrm{C}$, the particle sizes of the as-synthesized products were gradually increased, but they were still in nanoscale, as displayed in Figs. 6(c)-6(e). When the temperatures increased to $1300{ }^{\circ} \mathrm{C}$, the particle sizes of the as-synthesized products increased from nanoscale to microscale, and they were in the range of 150-250 nm, as shown in Fig. 6(f).

TEM measurement was employed to further analyze the microstructure and compositional uniformity of the as-synthesized products at 900 and $1300{ }^{\circ} \mathrm{C}$. Figure 7(a)
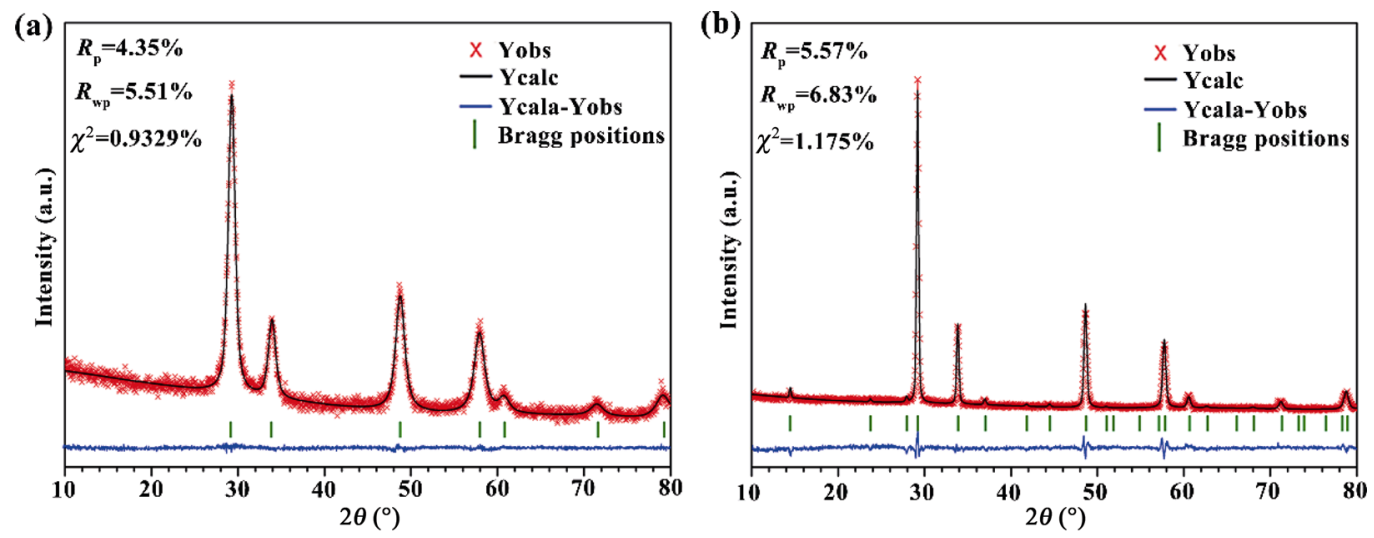

Fig. 5 (a) Rietveld refinement of the as-synthesized products at $900{ }^{\circ} \mathrm{C}$ in fluorite $(F m \overline{3} m)$ phase and (b) Rietveld refinement of the as-synthesized products at $1300{ }^{\circ} \mathrm{C}$ in pyrochlore $(F d \overline{3} m)$ phase. 

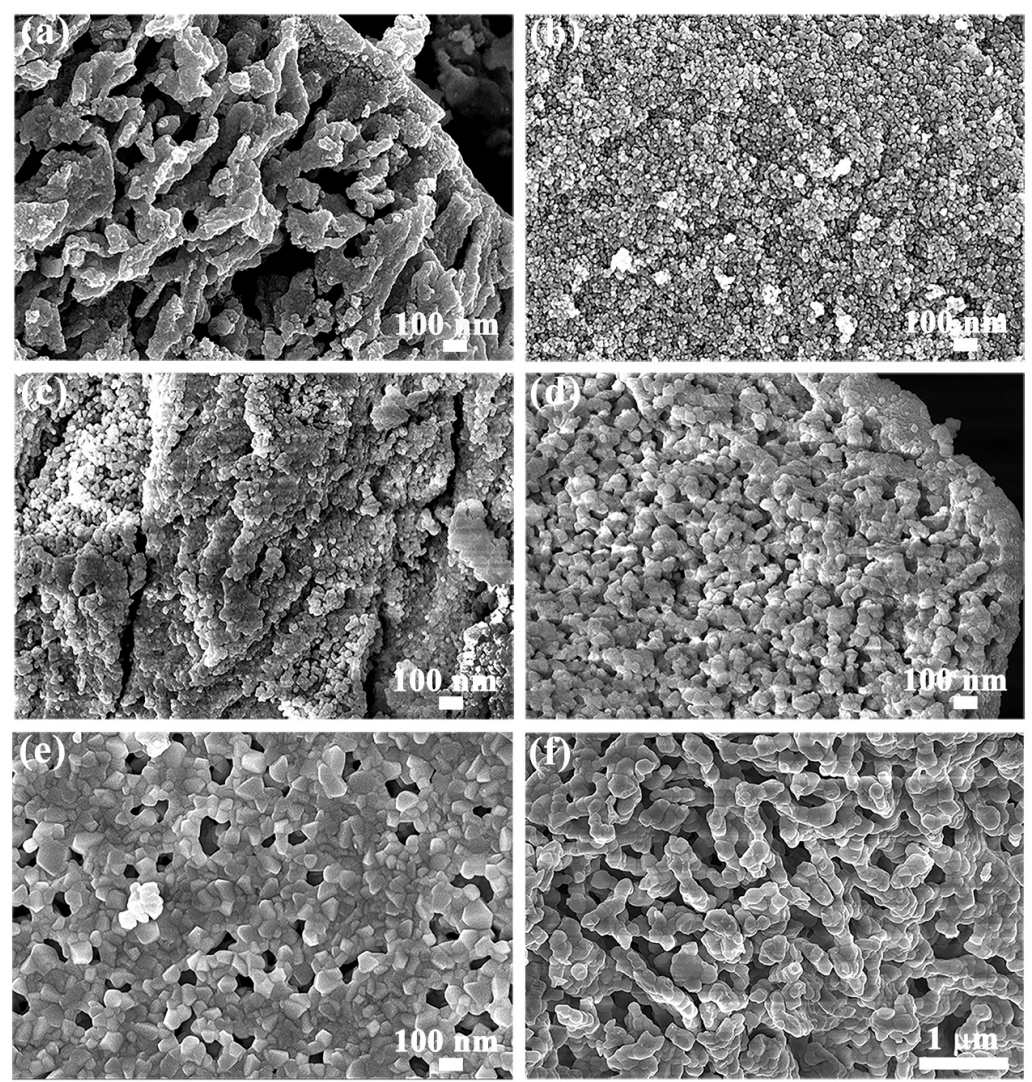

Fig. 6 SEM images of the as-synthesized products at different temperatures: (a) $800{ }^{\circ} \mathrm{C}$, (b) $900{ }^{\circ} \mathrm{C}$, (c) $1000{ }^{\circ} \mathrm{C}$, (d) $1100{ }^{\circ} \mathrm{C}$, (e) $1200{ }^{\circ} \mathrm{C}$, and (f) $1300{ }^{\circ} \mathrm{C}$.

is a typical TEM image of the as-synthesized products at $900{ }^{\circ} \mathrm{C}$, which presents numerous monodispersed high-purity and superfine nanoparticles with the average particle size of $11 \mathrm{~nm}$. This result further confirms the fact that they are superior to the as-synthesized nanopowders by combustion synthesis technique at $1200{ }^{\circ} \mathrm{C}$ [14]. In the selected area electron diffraction (SAED) image (Fig. 7(b)), the $\{111\},\{200\}$, $\{220\},\{311\},\{222\}$, and $\{331\}$ diffraction rings of the defective fluorite phase and the $\{420\}$ crystal plane were observed, indicating a complete crystallization. The high-resolution transmission electron microscopy (HRTEM) image (Fig. 7(c)) shows that they possessed a periodic lattice structure with two sets of fringes with the $d$-space of 0.304 and $0.263 \mathrm{~nm}$, corresponding to $\{111\}$ and $\{200\}$ planes of $\mathrm{RE}_{2} \mathrm{Zr}_{2} \mathrm{O}_{7}-1$ with fluorite phase, respectively. The scanning transmission electron microscopy (STEM) and corresponding EDS compositional maps (Fig. 7(d)) show that five metal elements were homogenously distributed without local ordering or element-rich regions in the as-synthesized products at $900{ }^{\circ} \mathrm{C}$. Figure $8(\mathrm{a})$ is a representative TEM image of the as-synthesized products at $1300{ }^{\circ} \mathrm{C}$, in which many individual submicron particles with the average particle size of $200 \mathrm{~nm}$ can be seen clearly. The SAED pattern implies that they possess the single crystal pyrochlore phase, as displayed in Fig. 8(b). HRTEM image (Fig. 8(c)) clearly shows a periodic lattice structure with a set of fringes with the $d$-space of $0.179 \mathrm{~nm}$, corresponding to the $\{315\}$ plane of pyrochlore phase. These further confirm the fact that the phase evolution of the as-synthesized powders occurred from fluorite to pyrochlore at $1300{ }^{\circ} \mathrm{C}$. The STEM-EDS compositional maps (Fig. 8(d)) show the uniform distribution of five metal elements without evident localization of any elements throughout the whole scanned area in the as-synthesized products at $1300{ }^{\circ} \mathrm{C}$. In addition, the atomic percentages of five metal elements for the as-synthesized products at 900 and $1300{ }^{\circ} \mathrm{C}$ are counted by EDS analysis, as listed in Table 3. Obviously, the atomic percentages of five metal elements are in good agreement with the stoichiometric ratios of $\mathrm{RE}_{2} \mathrm{Zr}_{2} \mathrm{O}_{7}-1$ for the as-synthesized products at 900 and $1300{ }^{\circ} \mathrm{C}$, which further confirms the compositional uniformity of the as-synthesized products at 900 and $1300{ }^{\circ} \mathrm{C}$. 


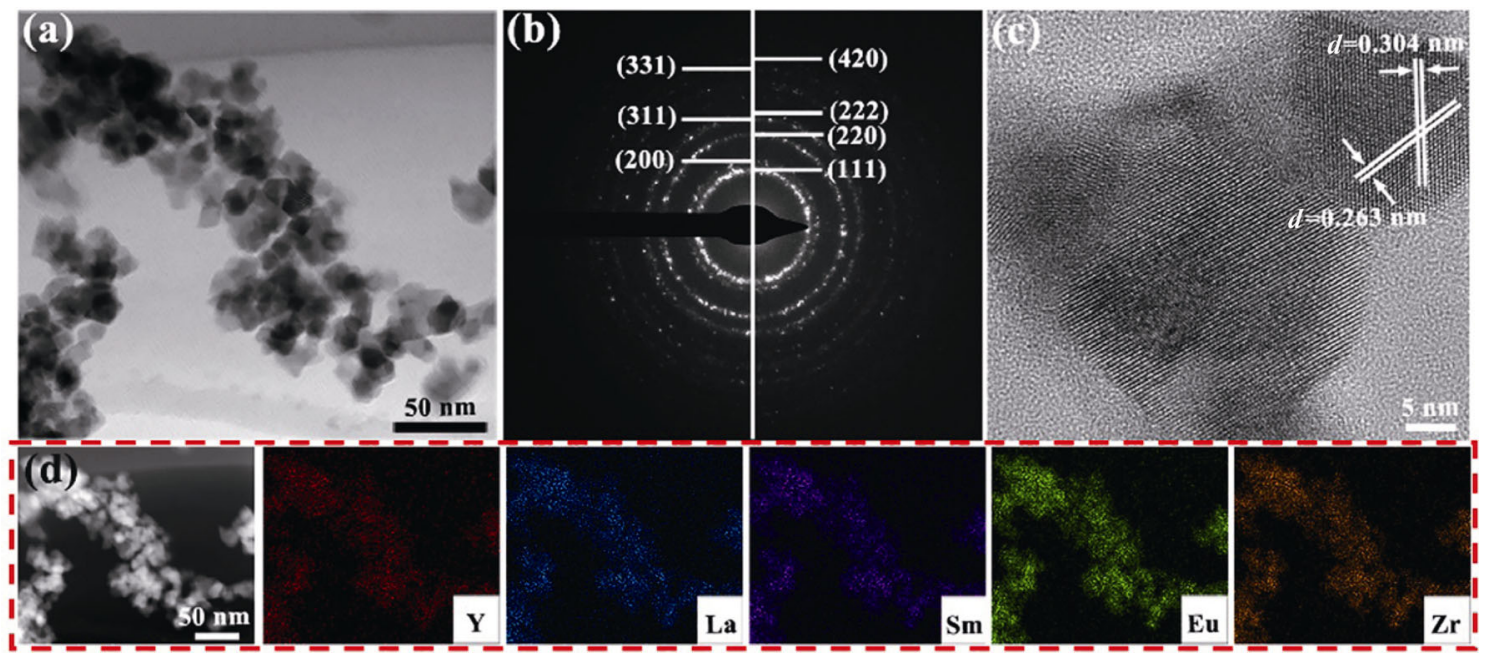

Fig. 7 TEM analysis of the as-synthesized products at $900{ }^{\circ} \mathrm{C}$ : (a) TEM image, (b) SAED pattern, (c) HRTEM image, and (d) STEM image and the corresponding EDS compositional maps.
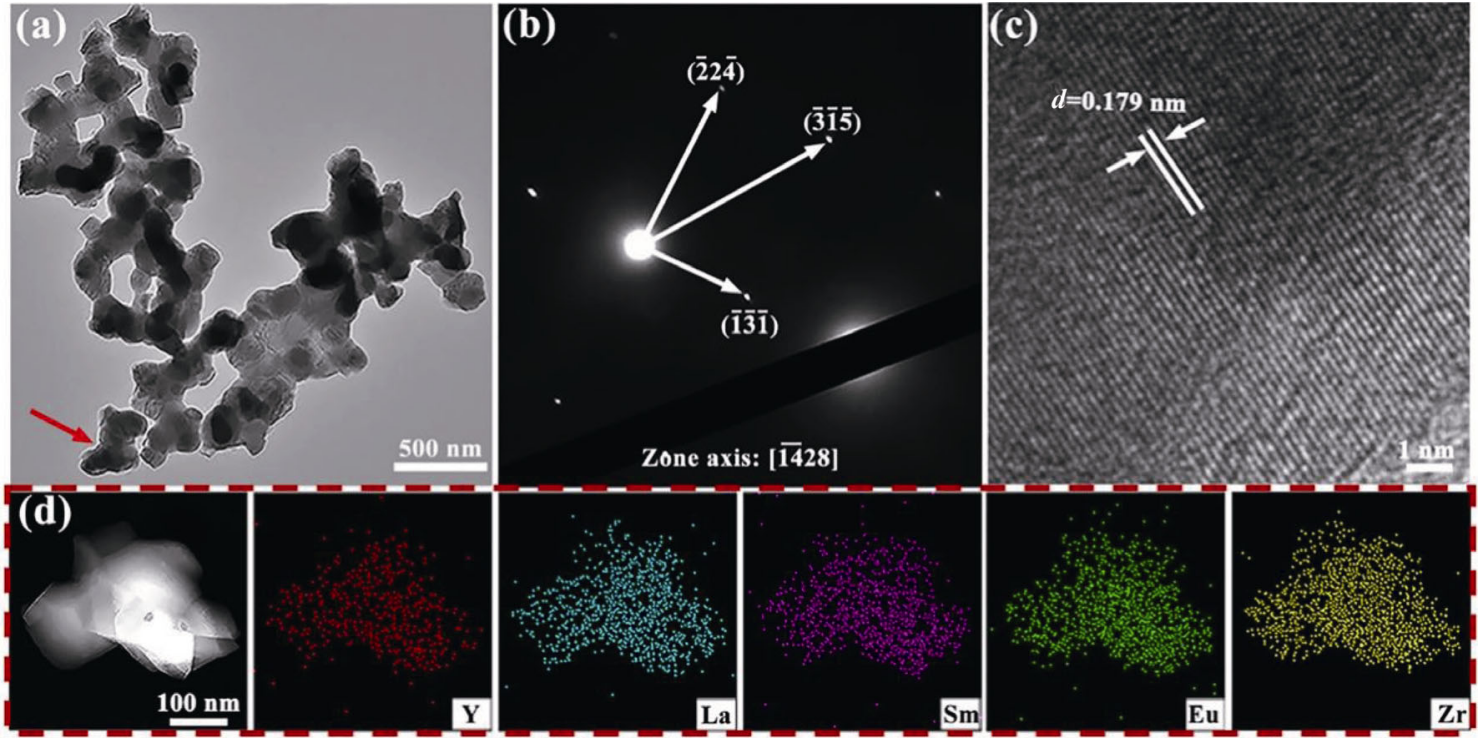

Fig. 8 TEM analysis of the as-synthesized products at $1300{ }^{\circ} \mathrm{C}$. (a) TEM image, (b) SAED pattern of the individual particle (indicated by red arrow in (a)), (c) HRTEM image of the individual particle (indicated by red arrow in (a)), and (d) STEM image and the corresponding EDS compositional maps.

Table 3 Elemental atomic percentage of the assynthesized products at 900 and $1300{ }^{\circ} \mathrm{C}$ by STEMEDS analyses

\begin{tabular}{|c|c|c|c|c|c|}
\hline \multirow{2}{*}{ Product } & \multicolumn{5}{|c|}{ Element (at \%) } \\
\hline & Y & $\mathrm{La}$ & $\mathrm{Sm}$ & $\mathrm{Eu}$ & $\mathrm{Zr}$ \\
\hline $\begin{array}{c}\mathrm{RE}_{2} \mathrm{Zr}_{2} \mathrm{O}_{7}-1 \\
\text { (at } 900{ }^{\circ} \mathrm{C} \text { ) }\end{array}$ & 6.51 & 6.73 & 6.42 & 6.70 & 25.67 \\
\hline $\begin{array}{l}\mathrm{RE}_{2} \mathrm{Zr}_{2} \mathrm{O}_{7}-1 \\
\text { (at } 1300{ }^{\circ} \mathrm{C} \text { ) }\end{array}$ & 6.48 & 6.79 & 6.37 & 6.78 & 25.02 \\
\hline
\end{tabular}

\section{Conclusions}

In summary, we have achieved the low-temperature synthesis of high-entropy zirconate nanopowders, namely $\mathrm{RE}_{2} \mathrm{Zr}_{2} \mathrm{O}_{7-1}$, via polymerized complex method for the first time. The polymeric precursor of $\mathrm{RE}_{2} \mathrm{Zr}_{2} \mathrm{O}_{7}-1$ was firstly synthesized by the polymerization and complexation reactions. Afterwards the $\mathrm{RE}_{2} \mathrm{Zr}_{2} \mathrm{O}_{7}-1$ powders were obtained by directly thermal decomposition of the polymeric precursor. As the synthesis temperature increased from 800 to $1300{ }^{\circ} \mathrm{C}$, the crystallinity degree, lattice strain, and particle size of the as-synthesized powders were gradually enhanced. The as-synthesized powders are composed of the fluorite phase in the range of $800-1200{ }^{\circ} \mathrm{C}$. When the synthesis temperature increased to $1300{ }^{\circ} \mathrm{C}$, the phase evolution of the 
as-synthesized powders occurred from fluorite to pyrochlore. It should be noted that the as-synthesized powders at $900{ }^{\circ} \mathrm{C}$ not only had the particle size of 11 $\mathrm{nm}$ without agglomeration, but also exhibited high purity and good compositional uniformity, which are of the highest quality among all the as-synthesized powders. This work will provide a new synthesis methodology for high-entropy zirconate nanopowders.

\section{Acknowledgements}

We acknowledge the financial support from the National Natural Science Foundation of China (Nos. 52122204 and 51972116), the Guangdong Basic and Applied Basic Research Foundation (Nos. 2019A1515012145 and 2021A1515010603), the Fundamental Research Foundation for the Central Universities (No. 2020ZYGXZR080), and the Creative Research Foundation of the Science and Technology on Thermostructural Composite Materials Laboratory (No. JCKYS2020607003).

\section{Electronic Supplementary Material}

Supplementary material is available in the online version of this article at https://doi.org/10.1007/s40145-021-0522-x.

\section{References}

[1] Rost CM, Sachet E, Borman T, et al. Entropy-stabilized oxides. Nat Commun 2015, 6: 8485.

[2] Tseng KP, Yang Q, McCormack SJ, et al. High-entropy, phase-constrained, lanthanide sesquioxide. $J$ Am Ceram Soc 2020, 103: 569-576.

[3] Li F, Zhou L, Liu JX, et al. High-entropy pyrochlores with low thermal conductivity for thermal barrier coating materials. J Adv Ceram 2019, 8: 576-582.

[4] Zhao ZF, Chen H, Xiang HM, et al. High entropy defective fluorite structured rare-earth niobates and tantalates for thermal barrier applications. $J$ Adv Ceram 2020, 9: 303311.

[5] Osenciat N, Bérardan D, Dragoe D, et al. Charge compensation mechanisms in Li-substituted high-entropy oxides and influence on Li superionic conductivity. $\mathrm{J} \mathrm{Am}$ Ceram Soc 2019, 102: 6156-6162.

[6] Witte R, Sarkar A, Kruk R, et al. High-entropy oxides: An emerging prospect for magnetic rare-earth transition metal perovskites. Phys Rev Mater 2019, 3: 034406.

[7] Jiang SC, Hu T, Gild J, et al. A new class of high-entropy perovskite oxides. Scripta Mater 2018, 142: 116-120.

[8] Wright AJ, Huang CY, Walock MJ, et al. Sand corrosion, thermal expansion, and ablation of medium- and high-entropy compositionally complex fluorite oxides. $J$ Am Ceram Soc 2021, 104: 448-462.

[9] Pianassola M, Loveday M, McMurray JW, et al. Solid-state synthesis of multicomponent equiatomic rare-earth oxides. $J$ Am Ceram Soc 2020, 103: 2908-2918.

[10] Zhu JT, Meng X, Zhang P, et al. Dual-phase rare-earthzirconate high-entropy ceramics with glass-like thermal conductivity. J Eur Ceram Soc 2021, 41: 2861-2869.

[11] Ren K, Wang QK, Shao G, et al. Multicomponent high-entropy zirconates with comprehensive properties for advanced thermal barrier coating. Scripta Mater 2020, 178: 382-386.

[12] Teng Z, Zhu LN, Tan YQ, et al. Synthesis and structures of high-entropy pyrochlore oxides. J Eur Ceram Soc 2020, 40: 1639-1643.

[13] Zhao ZF, Xiang HM, Dai FZ, et al. $\left(\mathrm{La}_{0.2} \mathrm{Ce}_{0.2} \mathrm{Nd}_{0.2} \mathrm{Sm}_{0.2} \mathrm{Eu}_{0.2}\right)_{2} \mathrm{Zr}_{2} \mathrm{O}_{7}$ : A novel high-entropy ceramic with low thermal conductivity and sluggish grain growth rate. J Mater Sci Technol 2019, 35: 2647-2651.

[14] Zhang KB, Li WW, Zeng JJ, et al. Preparation of $\left(\mathrm{La}_{0.2} \mathrm{Nd}_{0.2} \mathrm{Sm}_{0.2} \mathrm{Gd}_{0.2} \mathrm{Yb}_{0.2}\right)_{2} \mathrm{Zr}_{2} \mathrm{O}_{7}$ high-entropy transparent ceramic using combustion synthesized nanopowder. $J$ Alloys Compd 2020, 817: 153328.

[15] Uno M, Kosuga A, Okui M, et al. Photoelectrochemical study of lanthanide zirconium oxides, $\mathrm{Ln}_{2} \mathrm{Zr}_{2} \mathrm{O}_{7}(\mathrm{Ln}=\mathrm{La}$, Ce, Nd and Sm). J Alloys Compd 2006, 420: 291-297.

[16] Ma L, Ma WM, Sun XD, et al. Structure properties and sintering densification of $\mathrm{Gd}_{2} \mathrm{Zr}_{2} \mathrm{O}_{7}$ nanoparticles prepared via different acid combustion methods. J Rare Earths 2015, 33: 195-201.

[17] Toby BH. EXPGUI, a graphical user interface for GSAS. $J$ Appl Cryst 2001, 34: 210-213.

[18] Khorsand Zak A, Abd Majid WH, Abrishami ME, et al. $\mathrm{X}$-ray analysis of $\mathrm{ZnO}$ nanoparticles by Williamson-Hall and size-strain plot methods. Solid State Sci 2011, 13: 251-256.

[19] Chiu CW, Kao HCI, Sheu HS, et al. Phase transition and the thermal activated ordering of the ions with pyrochlore phase in $\mathrm{Ln}_{2} \mathrm{Zr}_{2} \mathrm{O}_{7}(\mathrm{Ln}=\mathrm{Sm}, \mathrm{Eu})$. J Chin Chem Soc 2010, 57: 925-931.

[20] Kong LG, Karatchevtseva I, Gregg DJ, et al. A novel chemical route to prepare $\mathrm{La}_{2} \mathrm{Zr}_{2} \mathrm{O}_{7}$ pyrochlore. $\mathrm{J} \mathrm{Am}$ Ceram Soc 2013, 96: 935-941.

[21] Popov VV, Menushenkov AP, Gaynanov BR, et al. Features of formation and evolution of crystal and local structures in nanocrystalline $\mathrm{Ln}_{2} \mathrm{Zr}_{2} \mathrm{O}_{7}(\mathrm{Ln}=\mathrm{La}-\mathrm{Tb}) . J$ Phys: Conf Ser 2017, 941: 012079.

[22] Saradhi MP, Ushakov SV, Navrotsky A. Fluoritepyrochlore transformation in $\mathrm{Eu}_{2} \mathrm{Zr}_{2} \mathrm{O}_{7}$-Direct calorimetric measurement of phase transition, formation and surface enthalpies. RSC Adv 2012, 2: 3328.

[23] Vegard L. Die Konstitution der mischkristalle und die 
raumfüllung der atome. Zeitschrift Für Physik 1921, 5: $17-26$.

Open Access This article is licensed under a Creative Commons Attribution 4.0 International License, which permits use, sharing, adaptation, distribution and reproduction in any medium or format, as long as you give appropriate credit to the original author(s) and the source, provide a link to the Creative Commons licence, and indicate if changes were made.
The images or other third party material in this article are included in the article's Creative Commons licence, unless indicated otherwise in a credit line to the material. If material is not included in the article's Creative Commons licence and your intended use is not permitted by statutory regulation or exceeds the permitted use, you will need to obtain permission directly from the copyright holder.

To view a copy of this licence, visit http://creativecommons. org/licenses/by/4.0/. 